\title{
ARGUMENTATIVE FEATURES OF INTERNATIONAL ENGLISH LANGUAGE TESTING SYSTEM (IELTS) ESSAYS: A RHETORICAL ANALYSIS ON SUCCESSFUL EXAM ESSAYS
}

\author{
Ririn Putra Ananda \\ English Education Postgraduate Program, Bengkulu University, Indonesia \\ Email: ririnananda@yahoo.com \\ Safnil Arsyad \\ English Education Postgraduate Program, Bengkulu University, Indonesia \\ Email: safnil@unib.ac.id \\ I Wayan Dharmayana \\ English Education Postgraduate Program, Bengkulu University, Indonesia \\ Email: dharmayana@gmail.com \\ DOI: $10.26858 /$ ijole.v2i1.4768
}

\begin{abstract}
An argument in academic writing is an essential element; it is used to convince readers that the writer's opinion or claim can be acceptable. However, this may be problematic for university students or new writers especially when writing in a language other than their first language such as Indonesians who take an international English writing test. The aim of this study is to identify and describe the rhetorical features of successful academic IELTS essays. Sixty academic essays were taken from six different common topics with band scores 8-9 (high quality essays) and were analyzed on elements of argument following Toulmin (1979). The results show that: a) the common sections found in the essays are lead in, thesis statement and deduction; b) the common elements of argument in the essays are claim, data and warrant; and c) the common types of argument structures of the essays are simple argument structure and strong argument structure. This implies that the essay sections, argument elements and argument structure can be used to describe the quality features of IELTS essay organization. It is suggested that in order to be able to write good quality essays in English, test takers must have a good command of essay sections, argument elements and argument structure type of good quality essays.
\end{abstract}

Keywords: rhetorical structure, examination essay, academic texts.

\section{INTRODUCTION}

Language test such as International English Language Testing System (IELTS) is used for many purposes in many contexts and chosen as one of the important aspects in professional contexts. This test is 'one of the household of the professional circle' (Leung \& Lewkowics, 2006, p. 222). The academic essay test is usually addressed for those willing to pursue their further study at a postgraduate institution in an English-speaking country such as an Indonesian who is willing to study in Australia, New Zealand or England. Therefore, four sections of IELTS such as listening reading, writing and speaking are usually administered in this test.

For the test takers, the hardest section of a standardised test such as IELTS is probably the writing section. Dickinson (2013) clearly states that the most problematic section of IELTS is writing test. It is also proven by the statistical 
data of mean band score for Academic IELTS; this writing section often gained the lowest mean band score of 5.5 in 2015-2017 (IELTSWORLDWIDE, 2017). In the last three years, many test takers failed in IELTS writing essay test than in other sections of the test such as speaking, reading, listening, vocabulary or grammar test. This is probably because presenting a reasoned argument in writing as the realisation of the analytical and critical style of thinking is hard for the university students (Ballard and Clanchy, 1984; Keraf, 1992). It will be even more difficult for those who do not use English as their first language (Hatch, 1992; Purves, 1988).

Writing an argumentative essay is an important skill for university students especially when they want to pursue their further study in an English speaking country such as Australia, England or the USA. University students may have studied rhetorical features of their first language that are reinforced by their education experience (Arsyad, 1999) but it will be a problematic challenge for them when they write in English; their language may tend to look foreign. Because of this reason, they will experience an ineffective communication in conveying their message in their English essay. Whereas, writing IELTS essays require test takers to have a good capability in writing to show their higher thinking process. Therefore, the students have to prepare themselves before taking the examination by studying the rhetorical features of successful essays first because different languages may have different rhetorical features of academic essays (Hinds, 1983 and Arsyad, 1999).

An essay must have some important sections and argument elements in order to be successful. Toulmin (1979) suggests that, an essay should consist of at least three main sections and a thesis statement may consist of up to six elements as presented below.

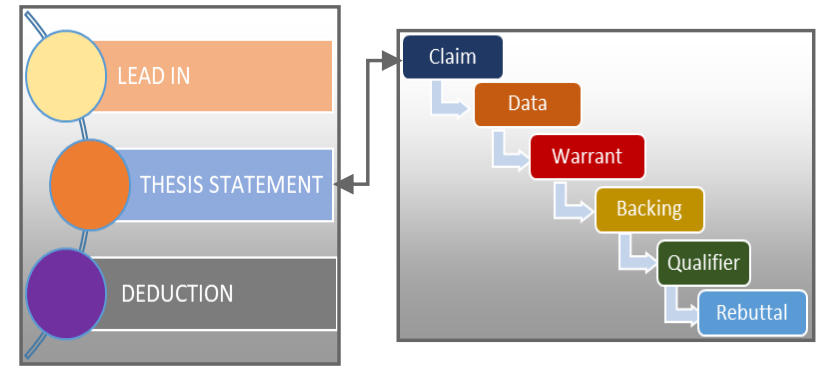

Figure 1: Argument Model of an Academic Essay (Toulmin, 1979)

As seen in Figure 1, according to Toulmin one of the three main sections of an essay must have a thesis statement with a claim and must be supported by up to six elements such as data, warrant, backing etc. The five elements of an argument are aimed at justifying the claim put forward by the writer so that the claim is strong and therefore acceptable.

Argumentative essays can be considered as one of the most difficult types of writing to write (Crasnich \& Lumbelli, 2005; Gárate \& Melero, 2005). The main problem in writing argumentative essays such as assigned in IELTS is the difficulty in organizing the argument to be as efficient argument because IELTS has its own limited numbers of words in essay to response the question (IELTS, 2017). Starkey (2004) explains that an important role of writer in writing a good essay is organizing the ideas into a logical and easy to follow format. Starkey adds that the organization of an essay will guide and organize the writing processes for the benefit of readers. If the test takers have a clear structure in their mind, then it will be easier for them to organize the content of the essay and will represent the knowledge of the topic in the best possible light to the reader.

There have been a large number of studies on the writing section of language testing such as IELTS. These studies have concentrated mainly on comparing IELTS essay writing and university essay writing in general (Moore and Morton, 2005). The results of this study revealed that IELTS essays have 
some similarities with the main genre of the essay in University although there are some important differences. In her study, Dickinson (2013), applied genre-based method to support students in writing IELTS essays as they are frequently found in this test. The results showed that the most problematic section in IELTS is writing section by the student. This method is offered not only to assist and prepare learners to find out their most immediate needs in achieving satisfactory scores in such tests, but also to allow them attain various goals in the future.

More recently, Suryaningsih (2014) conducted a study on the students' perception on IELTS and TOEFL writing tests. The results of this study showed that the test takers remarks IELTS and TOEFL tests diversely on three important perspectives: on the tests, in the tests and effects of the tests. Similarly, Ebrahimi (2014) conducted a status theme in the IELTS Task 2 essays. This study found that the nature of genre of essay writing directly imposed the selection of the theme. The after effects of these investigations could be used as a part of the IELTS planning and composing classes to help the authors, particularly EFL beginner researchers to accomplish palatable scores in composing papers for IELTS test.

Studies on writing essays have found students' problems in writing argumentative essays such as those assigned in standardized tests but none of them focused on the factors that can help test takers convince readers by using arguments in order to make sense for readers and how to build and develop the knowledge through successful writing. Argument in essay is very important to be used to strengthen reasons and persuade the readers by the language. Rusfandi (2015) explains that factors that might contribute to the persuasiveness of a given argument and student writers' knowledge-building through writing are important to study. In addition, evolving and evaluating arguments must be studied by the writer to embody, to initiate, or to simulate different kinds of interpersonal and textual interaction for reader consideration (Wu \& Allison, 2003). This is the rationale for this study; that is to answer the following questions:

1. What are the main sections found in successful academic International English Language Testing System (IELTS) essays?

2. What are the elements of argument found in successful academic International English Language Testing System (IELTS) essay? and

3. What are the different types of argument structures (if any) found in successful academic International English Language Testing System (IELTS) essay?

To answer the above questions, a rhetorical analysis was conducted on successful IELTS essays taken from IELTS material 2017 with six different common topics such as opinion, positive or negative, discussion, cause and solution, advantages and disadvantages and two type questions.

\section{METHODS}

An IELTS writing test consists of two tasks: task 1 and task 2 . In task 1, examinees are requested to write a short description of information presented in the form of a table, diagram while In task 2, examinees are asked to write an argumentative essay in response to a question or proposition. Tests designers demonstrates that test takers in their responses to the requirement of task 2 should provide general factual information, outline and/or present solution, justify an opinion, and evaluate ideas and evidence' (UCLES, 2002). The upcoming study only focused on Task 2 essay because it often poses heavier challenge for IELTS' test takers (Duigu, 2008). Another reason is the academic IELTS essay could be the main influence on students' developing understandings of what academic 
writing basically infold (Ebrahimi, 2014). In addition, Crowhurst (1991) says poor performance in argumentative writing is often posed by even native English speakers
1. The Corpus of the study

These essays in the corpus of this study came from the publicly available IELTS material 2017 sample essay answers with band score 8-9.

Table 1. The Distribution of Successful Essays of Academic IELTS in the Corpus of the study (IELTS Materials, 2017)

\begin{tabular}{clllc}
\hline No & \multicolumn{1}{c}{ Types of Question } & Code & Publisher & $\begin{array}{c}\text { Number of } \\
\text { Essay }\end{array}$ \\
\hline 1 & Opinion & OP & IELTS Materials & 10 \\
\hline 2 & Positive or Negative & PN & IELTS Materials & 10 \\
\hline 3 & Discussion & DS & IELTS Materials & 10 \\
\hline 4 & Cause and Solution & CS & IELTS Materials & 10 \\
\hline 5 & $\begin{array}{l}\text { Advantages and } \\
\text { Disadvantages }\end{array}$ & AD & IELTS Materials & 10 \\
\hline 6 & Two Type Questions & TQ & IELTS Materials & 10 \\
\hline Total & & & & 60
\end{tabular}

Essays of six different topics were analyzed in this research; these are opinion, positive or negative, discussion, cause and solution, advantages and disadvantages, and two types questions. The data were selected based on three criterion such as genre, English For Academic Purpose (EAP), and text type (Ebrahimi, 2014). In addition, Ebrahimi (2014) suggests that essay writing (task 2 essays of IELTS in this study) is qualified as a genre. According to Ebrahimi, it was also selected as the EAP essay writing and appropriate text type for this research as it contains characteristic of rhetorical features.

\section{Data Analysis}

The argument model used in this research was adapted from Toulmin (1979) consisting of lead in (LI), thesis statement (TS), claim (C), data (D), warrant (W), backing (B), qualifier (Q), Rebuttal (R) and deduction (DD). Six different common topics with band score 8-9 were analysed to represent the peculiar rhetorical features in successful Academic IELTS essay. To find out the answers of research questions in this study, the data were analysed by using text analysis technique using a simple sentence as the smallest unit analysis. Then, the sections of the essay and the elements of the argument in the essays were identified by the help of key words, discourse markers and inference. The rhetorical features occurring in the essays were calculated and compared with those found in the literature review. In addition, an inter-rater was employed to analyze and ensure the reliability of the rhetorical analysis on twelve essays (20\% of the total sample in the corpus of the study); the results show a high inter-rater reliability rates $(88,9 \%)$. Both raters had to work out the coding disagreement if it occurred till the satisfactory level was gained. Then, the two researchers analyzed the rhetorical features in other Academic IELTS essay in order to gain a full agreement result.

\section{RESULTS}

1. The Main Sections found in Academic IELTS Essay

The first analysis was on the main sections found of the essays and the results are as presented in table 2 below. 
Table 2. The Common Sections in the Successful IELTS Exam Essay

\begin{tabular}{clcccccccc}
\hline No & Section of Essay & \multicolumn{9}{c}{ Essay Topics } & \multicolumn{3}{c}{ Total } & $\%$ \\
\cline { 3 - 9 } & & OP & PN & DS & CS & AD & TQ & & \\
& & $\# 10$ & $\# 10$ & $\# 10$ & $\# 10$ & $\# 10$ & $\# 10$ & & \\
\hline 1. & Lead in & 10 & 10 & 10 & 10 & 10 & 10 & 60 & 100 \\
\hline 2. & Thesis Statement & 10 & 10 & 10 & 10 & 10 & 10 & 60 & 100 \\
\hline 3. & Deduction & 10 & 10 & 10 & 10 & 10 & 10 & 60 & 100 \\
\hline
\end{tabular}

As indicated in table 3, lead in, thesis statement and deduction are categorized as the obligatory sections in academic IELTS essay because the degree of the occurrence consistency is perfectly high. All of them appear in all or $100 \%$ in successful academic IELTS essay. Here are the examples of those three sections such as lead in, thesis statement and deduction. It indicates that those elements are obligatory sections which means that these sections are compulsory used in writing task 2 Academic IELTS essay as the main sections. Here are the examples of those three sections.

\section{Example 1}

Education for offenders during imprisonment as a method to reduce the rate of crime has evolved as a major topic of concern in today's society. While I agree that such a solution is effective to reduce crime, I am convinced that it is far from being the best method and there are many better ways of reducing crime. (About IELTS, 2017)

As can be seen from the example above, lead in is shown by the presence of the sentence about the fact of education for offenders in the beginning of the paragraph related to the response of the authors to the topic given. In this example, lead in is indicated as the opening sentence to arouse the readers interest, introduce the subject and establish the focus and direction for the essay. In this part, the authors have to look for the idea related to the topic and avoid copying the essay topic or they will not get the point at all. After stating the lead in to get the readers interest about the topic, the author must present the goal of the essay, this is where the thesis statement comes to its own. As shown on the table that this section is also the main section in the essay with the percentage $100 \%$. Below is an example.

\section{Example 2}

Currently, many parents tend to be busy working, and they need to rely on someone else to take care of their offspring. While some people think childcare organizations can offer the best care, I would argue that it is better for children to be looked after by their grandparents. (About IELTS, 2017)

As can be seen from example above, the thesis statement is shown by the presence of one sentence statement 'I would argue that it is better for children to be looked after by their grandparents'. This statement originally comes from the authors' opinion that focuses on telling the readers about the essay point. In other words, thesis statement is as the main idea that controls the argument of the essay itself.

The presented argument has been announced to convince the readers that the author's opinion can be acceptable. Therefore, at the end of the essay, the author must state and affirm the implication of what has been presented to support the author's position. This is where the deduction comes into its own. As shown on the table 2, the percentage of deduction is also perfectly high (100 \%). Below is an example of deduction. 


\section{Example 3}

In conclusion, an increase in the world's demand for natural resources is posing a number of threats to society. However, this can be handled by adopting above mentioned suggestions. (About IELTS, 2017)

As shown in the example above, the deduction is shown by the sentence "an increase in the world's demand for natural resources is posing a number of threats to society. "However, this can be handled by adopting above mentioned suggestions". This statement shows that there is a process of arguments explained by the author to ensure the reader arranged regularly to reach the implication of the presented arguments in order to make one last effort to ensure the reader, to suggest larger implications about the evidence that has been presented, and absolutely to provide a satisfying sense of closure.

2. The Elements of Argument used in Academic IELTS Essay

Six elements of argument as suggested by Toulmin (1979) were found in the data of this study. Table 3 below shows the result of data analysis.

Table 3. Elements of Argument in the IELTS Successful Exam Essays

\begin{tabular}{lcccccccc}
\hline Elements of & \multicolumn{9}{c}{ Essay Topics } & \multicolumn{2}{c}{ Total } & $\%$ \\
\cline { 2 - 7 } Argument & OP & PN & DS & CS & AD & TQ & & \\
& $\# 10$ & $\# 10$ & $\# 10$ & $\# 10$ & $\# 10$ & $\# 10$ & & \\
\hline Claim & 10 & 10 & 10 & 10 & 10 & 10 & 60 & 100 \\
\hline Data & 10 & 10 & 10 & 10 & 10 & 10 & 60 & 100 \\
\hline Warrant & 5 & 10 & 5 & 9 & 7 & 6 & 42 & 73 \\
\hline Backing & 0 & 3 & 1 & 10 & 3 & 4 & 21 & 35 \\
\hline Qualifier & 0 & 0 & 1 & 1 & 1 & 2 & 5 & 8,3 \\
\hline Rebuttal & 5 & 2 & 1 & 0 & 3 & 3 & 14 & 23,3 \\
\hline
\end{tabular}

Table 3 demonstrates that the highest percentage of argument elements found in the corpus of this study is claim and data with 60 or $100 \%$ appearance which indicates that the degree of consistency of the occurrence of these elements are perfectly high. It also indicates that those are as obligatory elements. As indicated from the table 3, lead in, thesis statement and deduction are indicated as the obligatory sections in academic IELTS essay because the degree of the occurrence consistency is perfectly high. All of them appear $100 \%$ in successful academic IELTS essay. Here are the examples of those three sections such as lead in, thesis statement and deduction. Below is an example.

\section{Example 4}

On the one hand, it is significant that school children should learn about their local history. Firstly, knowing about the past of their region or country will foster a sense of belonging and pride in each child. For example, by studying how' earlier generations fought and made sacrifices for the freedom of the country, Vietnamese youngsters will appreciate more the value of the way of life and liberty that they enjoy today (About IELTS, 2017)

As shown in the example above, the presence of claim is indicated by the word 'should learn about their local history' in the sentence'; this claim is categorized as claim of policy which show that a certain condition must exist. In addition, the example demonstrates that the 'claim' must be 
debatable so that the authors can be easier to argue for. In addition, this example demonstrates that academic IELTS essay claim or body part is used to present essays' goals, direction and scope, and is supported by evidence, examples, argumentation, expert opinion, statistics, and telling details. It indicates that the claim must be debatable. It must be argumentative. When the authors make a claim, the authors are arguing for a certain interpretation or understanding of the topic.

A good claim is specific, it makes a focused argument. However, the claim will be nothing without the presence of "data" as supporting sentence to make the claim more logical and persuasive. As shown on table 3, the percentage of data is $100 \%$. It indicates that this element is an obligatory element. Here is the example of data in one of the essays.

\section{Example 5}

On the one hand, it is significant that school children should learn about their local history.

(D) Firstly, knowing about the past of their region or country will foster a sense of belonging and pride in each child. For example, by studying how' earlier generations fought and made sacrifices for the freedom of the country, Vietnamese youngsters will appreciate more the value of the way of life and liberty that they enjoy today. Secondly, young children also learn about the origins and core values of their motherland through history lessons (About IELTS, 2017)

From the examples of data above, it demonstrates that data is shown by the presence of telling details and examples after stating the claim at first in order to support and strengthen the claim itself. In addition, the example demonstrates that the data takes important role because claim cannot stand alone without the data. The data is a part of considering the fundamental reasons needed to support the claim.

It turns out, this case implies that Information utilized as a part of the Academic IELTS essay is typically strong and persuasive argument. Although in fact, it could affect the readers in different way. Therefore, this is where the warrant comes into its own. As shown on table 3, the percentage of warrant is $73 \%$. It is indicated as conventional element. The example of warrant can be seen below.

\section{Example 6}

On the other hand, I believe this development has far more drawbacks. The first one is that travelling to remote natural areas can be risky if the travellers are not sufficiently prepared. For instance, the temperature at the South Pole is usually very low, which adversely affects people's health. Travelling to forests can also be dangerous as people have to face the risk of being attacked by animals. Also, since visiting isolated places often requires a large amount of investment in researching and ensuring the safety of travellers, the costs of travelling tend to be high. (W)Therefore, it seems like only scientists and rich people can afford this activity, so this development is likely to benefit only a small group of individuals. (About IELTS, 2017)

As shown on the example, the warrant is shown by the presence of the word "It seems like only scientist and rich people". This word indicates that there is a logical relationship or implication between the claim and the data. This example clearly demonstrates that the use of warrant is to make a relation or implication between the claim and data stronger. However if claim and data are clear enough and do not make an ambiguity in readers' mind, then the use of warrant could be ignored. 
In particular situation, warrant is needed to be examined whether the statement or assumption in this element is relevant or rational with the claim and data or not. Therefore, the use of another element such as backing is needed. As shown on table 3, backing was found in academic IELTS essay with percentage $35 \%$ indicated as the optional element. Below is the example of backing.

\section{Ex]ample 7}

Yet the world is a very different place from how it looked in 1945, which has led some people to question the need for a powerful organisation like the UN. (B) In particular, there are some proponents of free trade who argue that competition and not cooperation between nations is the fastest way to pursue economic development. (About IELTS, 2017)

From the example above, the backing is shown by the presence of the sentence "some proponents of free trade who argue that..."the role of this sentence is to justify assumptions stated in the warrant proven by giving an evidence such as information from the particular people whose credibility could be accepted by the readers to strengthen the assumption stated in the warrant.

On the other hand, in one situation the presented argument must be challenged by explaining and supporting the claim with different point of view. This is where another optional element called as rebuttal comes into its own. As shown on table 3, rebuttal was found in academic IELTS essay with the percentage $23.3 \%$ indicated as optional element. Below is an example of rebuttal.

\section{Example 8}

However, I would argue that there are much better methods of ensuring road safety. The first one is to have stricter punishments for driving offenders. For example, people who break traffic rules should be required to pay huge fines or be banned permanently from commuting on the street. This makes commuters more likely to respect the law, and traffic accidents can be limited. Another solution is to encourage people to use public transport rather than private vehicles. This can be done by reducing the price and increasing the frequency of buses and tubes to make it more convenient for users. (About IELTS, 2017)

This example demonstrates that the rebuttal is shown by the presence of the word "however", it becomes the characteristic of the rebuttal because the authors use this word to defend their argument and clearly state that their own argument/position is the best one and can be more accepted by the readers. This example is kind of rebuttal which is written in the form of complete sub-section of argument; this can be, because rebuttal is actually argument in itself, so it may include others subsections together such as claim, data, warrant and etc.

In argument, the authors must bring the strong data related to the topic given, however sometimes there is one condition that the data cannot be applied universally. Therefore, this is where the qualifiers come into its own. As shown on the table 3, qualifier was found in academic IELTS essay with the percentage 8,3 $\%$ indicated as optional element. Here is the example of qualifier.

\section{Example 9}

When there is no limit to the indulgence parents show toward their kids, these children will become needy and dependent, and therefore are unable to live on their own. In some cultures like Vietnam, parents pick up their kids at school even during high school, buy their clothes and cook at home. Children do not have to do anything, which is mainly why many of them cannot stay away from their parents and live independently even when they are in their 20s. (About IELTS, 2017)

As indicated from example above, the last sub-section is qualifier which shown by the presence of words such as 'some' 'most', 'usually', 'always' or 'sometimes' combined 
with the sentence to hence range from strong claim. This sub-section is used to indicate the strength of the leap from the data to the warrant and may limit how universally the claim applies.

\section{The Different Types of Argument Structures}

The six elements of argument examined in this research can be classified into two different types of argument structure: simple argument structure and strong argument structure. This structure below is used to conduct the main body part of the essay. To prove whether the thesis statement of the essay is true or not, the test takers need to give supporting sentences/paragraph to convince the examinees that the authors' side is correct one. Therefore, these elements below are the important ones in conducting a good argument. In the other words without the position of the claim will be stronger if the test takers use these elements.

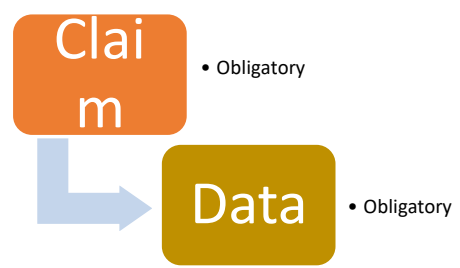

Figure 3: The Structure of Simple Argument Structure

As shown on figure 3, the simple argument structure consisting of claim and data found in Academic IELTS essay. In this pattern, the conclusion is made after the reasons that support a claim. Although these two elements exist, it does not mean that the argument is acceptable or appropriate. Claims or appropriate conclusions should indicate the relevant relationship between ground and claim. Therefore, it needs to be reviewed carefully, whether the claim has been formulated clearly. Claim is clearly visible from a clear and unambiguous language structure. Below is an example.

\section{Example 10}

Claim: On the other hand, I consider that education has a complementary role to play.

Data : Firstly, in schools, students should study some aspects of the law which affect their lives. Having some knowledge of the law, students are better prepared to avoid situations which may involve them in crime or becoming a victim. For example, youngsters must study the important laws about driving and road safety. Secondly, in prisons themselves, educational programmes must aim to provide prisoners with skills and qualifications to find work when they are released. (About IELTS, 2017)

From the example above, claim and data are used as the element of the argument. Claim is shown from the presence of the sentence "education has a complementary role to play" the author attempt to convey the claim of fact proven by the following data after the claim. It consists of telling details shown by the words "firstly, secondly" and example shown by the words "for instance". This structure is indicated as the simplest structure where the author only put a claim and relevant justification regarding to the topic given.

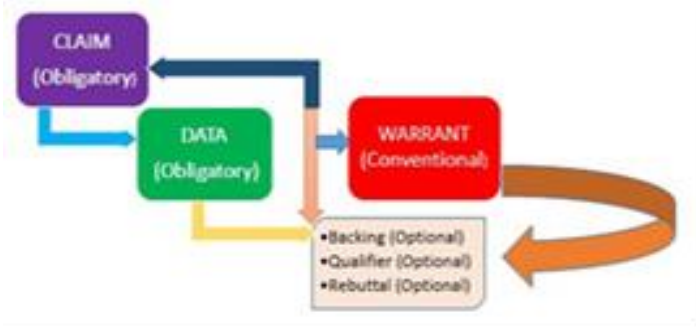

Figure 4: The Structure of Strong Argument Structure

As shown in figure 4, there are three compulsory elements to elaborate the argument in writing essays academic IELTS 
task 2. They are claim and data, then the relationship between claim and data affirmed by warrant as the conventional element which means that this element also used as the primary elements in writing essay. On the other hand, there are others elements used as optional elements that can strengthen the arguments such as backing, modal qualifier and rebuttal which is indicated as complementary elements. It indicates that those elements are not always used in elaborating the essay but these elements are available to be chosen in supporting and strengthening the claim. Therefore, the example below present the different type of structure found in academic IELTS essay categorized as strong argument structure. Below is an example.

\section{Example 11}

Claim : I accept that education for prisoners may contribute to the reduction of the crime rate.

Data: The primary reason is that such a form of education could provide offenders with the working skills that are essential when they return to the community. With fortified job prospects, prisoners may therefore earn a living after leaving the prison and are less likely to commit a crime again. Another significant reason is that education could show the offenders that they are still appreciated by society. By this way, they may feel an enhanced sense of humanity and community, and become better citizens after their prison years.

Warrant : These people may then inspire many others in the public to live without crime.

Rebuttal : However, I am firmly of the opinion that education for offenders is not the best solution to reduce crime. This form of education is offered only to those who have committed a crime, and therefore has far less preventive value, compared to other stronger solutions. For example, severe punishments such as longer imprisonment for criminals could deter criminal acts by many people in the public who have the intention to carry out a crime. There are also other educational methods that may have a stronger and more long-lasting impact on the reduction of crime. An excellent example of this is crime education at school, which helps equip students with the necessary knowledge about crime and crime prevention. This measure is undeniably a more sustainable crimefighting solution than education for criminals. (About IELTS, 2017)

As shown on the example above, one of strong argument structure is shown by the present of argument elements such as claim, data, warrant and rebuttal. This example demonstrates the use of the obligatory elements and optional element namely rebuttal completing this argument structure perfectly. The "rebuttal" is shown by the presence of the collaboration among the elements such as claim, data and warrant. Clearly, rebuttal is the argument in itself, so the use of the combination of other elements to become one paragraph is freely included.

\section{DISCUSSION}

The first objective of this research is to identify the sections in Academic IELTS and the results show that academic IELTS essays commonly consist of three sections such as lead in, thesis statement and deduction. It indicates that academic IELTS requires the completed sections to organize the examination essay just like other academic essays. This finding is in line with a study by Zemach and Rumisek (2005) and Duigu (2008) who found that in Academic IELTS essay must have three sections typically just like writing other academic essay consisting of lead in, thesis statement, and deduction. Lead in is indicated as the introductory sentence of the essay that focuses on getting the readers' interest (Oshima \& Hogue, 1991; Saraka, 1998). Second, thesis statement is indicated as the authors opinion regarding the topic to let 
the reader know about the aspect of the topic being dealt with and the stand (attitude) taken by the authors to the topic (Duigu, 2008; Zemach and Rumisek, 2005). The last section of the essay is deduction demonstrated as summarizing of the main points, concluding statements drawn from the points made in the main body, and recommendation of action to be taken (Trzeciak and Mackay,1994).

The second objective of this research is to identify and describe the elements of argument in Academic IELTS essay task 2. The results show that there are six elements commonly used in academic IELTS essay, but the most commonly used are claim, data, and warrant. It indicates that the majority of academic IELTS essay tends to use one sided argumentation proven by the lower percentage of rebuttal. As Rusfandi (2015) explains that one side argumentation means the argument provides claim, data and warrant without considering opposing view or rebuttal. It implies that academic IELTS requires relevant justification or response toward the topic given. This finding is in line with Toulmin (1987) and Rothenberg (1988) who explain that claim, data and warrant are the most commonly used in the essay because those three elements are the primary elements in essay. In other words, these elements in an essay are compulsory and others such as backing, qualifier and rebuttal are as complementary elements meaning that these elements are not compulsory one. In other words, these elements are free to be chosen to support the claim stronger.

The last objective of this research is to identify and describe the different types of argument structures in academic IELTS essay. The results show that there are commonly two types of argument structures in Academic IELTS such as simple argument structure consisting of claim and data and strong argument structure consisting of claim, data as obligatory elements, warrant as conventional element, backing, qualifier and rebuttal as the optional element. However, the most commonly structure used is strong argument structure proven by the frequency of the general presence. It indicates that essay containing this structure will have a good quality essay and requires the authors to have high quality thinking process to answer the essay about the topic given in writing. This finding is in line with that of Toulmin (1979) and Golden et al (1976) who explain that the use of claim, data and warrant as the primary elements and backing, qualifier, rebuttal as the complementary element are required as the important aspects to determine the quality of the essay. In addition, academic IELTS essay task 2 requires the test takers to assess their ability to present and justify an opinion, opinions and implication, to compare and contrast the evidence, to present the solution to a problem, and to evaluate and challenge ideas and evidence or an argument (Duigu, 2008). Furthermore, Duigu (2008) explains that the goal of this test is their capability in explaining the point in the argument suitably about a common issue but not for their knowledge. In the other words, academic IELTS essay task 2 requires test takers to have a higher order thinking process (Rusfandi, 2015). As long as the explanation is relevant to the topic and it can convince the reader that the authors' argument is right, so the argument will be accepted.

\section{CONCLUSION, LIMITATION AND SUGGESTION}

This study found that the common sections in successful academic IELTS essay consist of lead in, thesis statement and deduction which implies that academic IELTS requires the completed sections to organize the examination essay just like other academic essay. In term of elements of argument, the successful essays consist of three elements: as 
claim, data and warrant. It indicates that these are the primary elements of an essay. In terms of the types of argument structures, two structure types were found: simple argument structure and strong argument structure. However, based on the frequency, strong argument structure is more frequently chosen than the simple one in academic IELTS. In indicates that these essay elements are considered to reach high quality essay.

The present study has its limitations. One limitation is that this study did not measure the degree to which an individual essay integrated to the element of argument in academic IELTS essay. This study measured only the presence of rhetorical features such as lead in, thesis statement, claim, data, warrant, backing, modal qualifier, and rebuttal and deduction. The researcher didn't focus whether the presence of the rhetorical features does or does not enhance the persuasiveness of information presented in the essay is unknown in this study.

From the limitation, it is suggested that future researcher can conduct another research about writing argument structures in academic IELTS essay and implement a more comprehensive coding system in measuring should be evolved in order to discover whether the use of particular element of arguments in Academic IELTS essays affect the persuasiveness of their given arguments.

\section{REFERENCES}

About the IELTS. (2013). International English Language Testing System (IELTS). Retrieved from https://www.ielts.org/what-isielts/ielts-introduction

About the TOEFL. (2013). English Testing Services (ETS). Retrieved from https://www.ets.org/ toefl/ibt/about/

About IELTS (2017). Academic IELTS Essays Sample http://ieltsmaterial.com/writing/
About IELTS. (2017). statistic data Worldwide https://www.ielts.org/ teaching-andresearch/test-statistics/

About IELTS and TOEFL. (2017) test format https://www.ielts.org/about-the-test/ test-format-in-detail

Arsyad, S. (1999). 'The Indonesian and English argument structure: a crosscultural rhetoric of argumentative texts', Australian Review of Applied Linguistics, 22 (2): 85-102.

Ballard, B \& Clanchy, J. (1984). Study abroad: A manual for Asian students, Longmans, Kuala Lumpur.

Crowhurst, M. (1991). 'Interrelationship between reading and writing persuasive discourse.' Research in the Teaching of English, Vol. 4, 314-334.

Crasnich, S. \& Lumbelli, L. (2005). Improving Argumentative Writing by Fostering Argumentative Speech. In Gert Rijlaarsdam, et. al. (Eds.). Effective Learning and Teaching of Writing: A Handbook of Writing in Education Second Edition. (pp. 181-196). Boston: Springer Science and Business Media, Inc.

Dickinson, P. (2013). A Genre-based Approach to Preparing for IELTS and TOEFL Essay Writing Tasks. Niigata University of International and Information Faculty of Information and Culture, Vol. 16, pp: 1-9.

Duigu, G. (2008) Essay Writing For English Test. Australia, Academic English Press

Ebrahimi, S. F. (2014). The status of theme in the IELTS task 2 essay. Iran. Shadegan Branch, Islamic Azad University, Shadegan. Vol. 3, 339-397

Gárate, M/ \& Melero, A. (2005). Teaching How to Write Argumentative Texts at Primary School in Gertrijlaarsdam, et. al. (eds.). Effective Learning and Teaching of Writing: A Handbook of Writing in Education Second Edition. 
Golden, J. L., Goodwin F. Berquist, and William E. C. (1976). The Rhetoric of Western Thought. Dubuque, Iowa: Kendall/Hunt Publishing Company.

Hatch, E. (1992). Discourse and Language Education. Cambridge University Press.

Keraf, G. (1992). Argumen dan Narasi. Jakarta. Gramedia.

Leung, C. \& Lewkowicz, J. (2006). 'Expanding horizons and unresolved conundrums: Language testing and assessment',TESOL Quarterly, 40 (1), 211-234.

Moore, T., \& Morton, J. (2005). Dimensions of difference: a comparison of university writing and IELTS writing. Journal of English for Academic Purposes, 4(1), 43-66. doi:10.1016/j.jeap.2004.02.001

Oshima A. \& Hogue A. (1991). Writing Academic English

Purves D.(1988) Body and brain: A trophic theory of neural connections.(Harvard University Press, Cambridge, MA)

Rothenberg, A.T. (1985) Elements of Argument, New York: ST Main's press.

Rusfandi. (2015). Argument-Counterargument Structure in Indonesian EFL Learners' English Argumentative Essays: A Dialogic Concept of Writing. RELC Journal, 46(2), 181-197.

Toulmin, S. E. (2003). The Uses of Argument Updated Edition, New York: Cambridge University Press.

(1984). The Uses of Argument. Cambridge: Cambridge University Press.

(1958). The Uses of Argument. Cambridge: Cambridge University Press.

Toulmin, S. E. et al. (1979) An Introduction to reasoning. New York: MacMillan.
Trzeciak, J. K., and Mackay, S.E. (1994). Study for Academic Writing. Hemel Hempstead: Phoenix ELT.

Saraka (1988), From Paragraph To Essay: Concepts and Practices, Jakarta: DEPDIKBUD.

Starkey, L. (2004). How to Write Great Essays, New York : Learning Express.

Suryaningsih, Hartati, (2014) "Students' Perceptions of International English Language Testing System (IELTS) and Test of English as a Foreign Language (TOEFL) Tests". Theses and Dissertations. Paper 1235.

UCLES. (2002) International English Language testing system. Available at: http://www. cambridgeenglish.org/exam/academic/ bg ielts.html/ .

Zemach, D. E \& Rumisek, L. E. (2005). Academic Writing from Paragraph to essay. MacMillan: MacMillan Publisher. 